\title{
Efficacy of an Intensive Outpatient Rehabilitation Program in Alcoholism: Predictors of Outcome 6 Months after Treatment
}

\author{
Miriam Bottlender Michael Soyka \\ Department of Psychiatry, Ludwig Maximilians University, Munich, Germany
}

\section{Key Words}

Alcoholism · Alcoholism, outpatient treatment and prognosis - Outpatient rehabilitation program, follow-up - Outpatient rehabilitation program, outcome

\begin{abstract}
Treatment of alcohol-dependent patients was primarily focused on inpatient settings in the past decades. The efficacy of these treatment programs has been evaluated in several studies and proven to be sufficient. However, with regard to the increasing costs in public healthcare systems, questions about alternative treatment strategies have been raised. Meanwhile, there is growing evidence that outpatient treatment might be comparably effective as inpatient treatment, at least for subgroups of alcohol dependents. On that background, the present study aimed to evaluate the efficacy of a high-structured outpatient treatment program in 103 alcohol-dependent patients. 74 patients $(72 \%)$ terminated the outpatient treatment regularly. At 6 months' follow-up, 95\% patients were successfully located and personally re-interviewed. Analyses revealed that 65 patients (64\%) were abstinent at the 6-month follow-up evaluation and 37 patients $(36 \%)$ were judged to be non-abstinent. Pretreatment variables which were found to have a negative
\end{abstract}

impact (non-abstinence) on the 6-month outcome after treatment were a higher severity of alcohol dependence measured by a longer duration of alcohol dependence, a higher number of prior treatments and a stronger alcohol craving (measured by the Obsessive Compulsive Drinking Scale). Further patients with a higher degree of psychopathology measured by the Beck Depression Inventory (depression) and State-Trait Anxiety Inventory (anxiety) relapsed more often. In summary, results of this study indicate a favorable outcome of socially stable alcohol-dependent patients and patients with a lower degree of depression, anxiety and craving in an intensive outpatient rehabilitation program.

Copyright $\odot 2005$ S. Karger AG, Basel

\section{Introduction}

Per capita alcohol consumption of more than 10 liters/ year in Germany is one of the highest in the world. At least 1.6 million Germans are currently alcohol-dependent, about 3 million individuals exhibit alcohol dependence in remission and more than 2 million persons currently abuse alcohol [1]; thus, alcohol dependence is one of the most serious, expensive and socially disruptive health issues. For a long period of time, alcohol treatment

\section{KARGER}

Fax +4161306 1234 E-Mail karger@karger.ch www.karger.com 
(rehabilitation programs in Germany and Europe) focused nearly exclusively on mid- to long-term inpatient treatment of alcoholism. The efficacy of this treatment has been addressed in a number of catamnestic studies which indicate a favorable $(>40 \%)$ abstinence rate in a 4-year follow-up (MEAT study [2]). Nevertheless, with regard to the increasing costs in health service systems and the reduction of the number of inpatient treatment facilities, a need of alternative strategies as for example outpatient treatment emerges.

It is only since the early 1990s that outpatient rehabilitation programs have been funded by health insurers in Germany, but to date little research has focused on this issue and the number of patients included in outpatient rehabilitation programs still is much smaller than those treated as inpatients in special alcohol clinics (approx. 11,801 outpatients vs. 36,083 inpatients [1]).

An intensive 6- to 9-month treatment program for alcohol-dependent patients, one of the first of its kind in Germany, was initiated already in 1990 in the greater Munich area (Dachau) and a first retrospective 18- to 24month catamnestic study was published in 1997 indicating a favorable treatment outcome (abstinence rate 48\%) [3]. On that background the present study aimed to investigate the efficacy of a high-structured outpatient treatment program for alcoholism. Considering that previous studies [4-6] mainly revealed that severity of alcohol dependence, number of previous treatments, age of onset, and co-morbid psychopathology were predictive for subsequent relapses, a further aim was to analyze the impact of these and other pre-treatment variables on the 6-month outcome of the treatment program.

\section{Methods}

\section{Study Design}

During a period of 12 months, 103 consecutively recruited alcohol-dependent patients were included in a prospective study on an outpatient treatment program for alcoholism. The outpatient facility offers a high-structured, intensive two-phase treatment model with a similar setting to conventional inpatient treatment with respect to intensity and quality of psychotherapy. The model has been described in detail $[7,8]$. An initial 12-week motivational phase is followed by the 6- to 9-month rehabilitation phase which is the subject of research. The rehabilitation is usually paid for phase by pension funds.

The therapeutic concept of the rehabilitation phase is an integrative, eclectic one and includes different psychotherapeutic methods and approaches. The therapy program comprises 80 (maximum) to 120 therapy sessions, mostly group therapy, but also individual therapy, including behavioral/cognitive, psychodynamic and systemic oriented therapy sessions. Basic elements are depth psychology, be- havioral/cognitive therapy and therapeutic conversation according to Rogers. During the 6- to 9- (average 8) month rehabilitation phase, the patient is seen 2-3 times/week. During rehabilitation, weekly sessions of individual therapy and 12 family therapy sessions will be offered. Optional elements are self-help groups, but also other elements such as psychodrama or muscular relaxation, among others. During the entire treatment, abstinence is checked by repeated breath-analyzer tests as well as blood laboratory tests.

The therapeutic team comprises $2-3$ psychiatrists (physicians), 2 full-time psychotherapists, several part-time psychologists, and 1 social worker. As for inpatient treatment, the clinical staff of the outpatient clinic must fulfill qualifications to be acknowledged by pension funds as therapists.

Patients included in the study fulfilled the ICD-10 and DSM-IV criteria for alcohol dependence and gave their written informed consent to participate in the study. Exclusion criteria were severe organic, psychiatric and mental disorders (e.g., decompensated liver cirrhosis, suicidality, acute psychosis, Korsakow syndrome).

The assessment of sociodemographic and alcohol-related data followed the guidelines of the German Society for Addiction Research and Therapy [9] and using the EuropASI [10]. In addition, the patients underwent a self-rating State-Trait Anxiety Inventory (STAI) [11], the Beck Depression Inventory (BDI) [12] and the Obsessive Compulsive Drinking Scale (OCDS) [13]. With exception of the self-rating scales, assessment of patients was carried out by trained research assistants in a structured, face-to-face interview. At the time of the patient's first assessment at the beginning of the treatment program (pre-test), the patients were abstinent for at least 30 days. Thus an influence of a prolonged withdrawal syndrome on the assessed variables can be excluded. Further patient assessments were carried out at the end of the outpatient treatment (post-test) and 6 months later (follow-up).

\section{Definition of Outcome Criteria}

Relapse during the outpatient treatment was defined as the intake of any amount of alcohol. Recurrent relapses (more than two) or refusing to participate in the treatment program led to a disciplinary early discharge.

Outcome description at the 6-month follow-up was based on the classification proposed by Feuerlein and Küfner [2]. According to this classification, patients were judged to be abstinent (no subjective reports or objective indications of alcohol consumption), improved (during the last 6 months no more than three drinking periods lasting for less than 1 week (lapses) or $<30 \mathrm{~g}$ (female) or $<60 \mathrm{~g}$ (male) alcohol per day on a regular basis, no signs of pathological drinking, neither physical nor psychiatric disorders nor inpatient treatments due to alcohol consumption) or relapsed (more than three lapses or regular consumption of $>30 / 60 \mathrm{~g}$ alcohol per day, alcohol-related disorders or inpatient treatments during the last 6 months).

\section{Data Analyses}

Selection of pre-treatment variables which were analyzed concerning their impact on the 6-month outcome was mainly based on the findings from previous outcome studies [4-6, 14] and included sociodemographic data (age, sex, marital status and employment status) and alcohol-related data (age at onset of alcohol dependence, duration of alcohol dependence, daily alcohol consumption before treatment, previous treatment for alcohol dependence, in-patient or outpatient treatment, number of prior detoxifications, previous 
Alcoholics Anonymous contact, previous dropout from treatment programs, length of previous abstinence, drinking environment, family history for alcohol dependence and co-morbid benzodiazepine dependence). In addition, the influence of psychopathological symptoms (anxiety (assessed with the STAI), depression (assessed with the BDI) and craving for alcohol (assessed with the OCDS)) and the extent of satisfaction with employment status, partnership, friends or health were considered in the analyses.

Statistical analyses were carried out using the SPSS 11.0 Software for Windows. Group differences for continuous variables were compared by using the t test, non-parametric variables were compared using the Mann-Whitney U test. Group differences for all categorical variables were evaluated using the $\chi^{2}$ statistics. A $p$ value of $<0.05$ (two-tailed) was considered as statistically significant.

\section{Results}

Patients' Characteristics at the Beginning of the Outpatient Treatment

The total of 103 included patients consisted of 62 male and 41 female patients. One male patient died 2 months after the start of therapy (not alcohol-related) and was excluded from statistical analyses. The mean age of patients was $45( \pm 8)$ years. The mean age at onset of alcohol dependence was $29( \pm 11)$ years with a mean duration of $15( \pm 9)$ years. The patients reported an average daily alcohol consumption of $193( \pm 102) \mathrm{g}$ in the months prior to treatment. $35 \%$ of the patients had undergone prior alcoholism therapy. $20 \%$ of all the patients had taken part in outpatient treatments and $27 \%$ in inpatient treatments. $59 \%$ of the patients were married, $24 \%$ divorced, $15 \%$ single and $2 \%$ widowed. $81 \%$ of the patients had a regular employment with a mean monthly income of EUR 1,540 $( \pm 1,035)$.

\section{Relapse during the Outpatient Treatment and Dropout Ratio}

70 patients $(69 \%)$ were abstinent during the whole treatment, while 32 patients $(31 \%)$ relapsed during treatment. From the latter group, 14 patients $(13 \%)$ again reached abstinence after relapse and remained in the treatment program. The relapse had a duration of maximum 3 days in 17 patients (16\%) and a duration of more than 3 days in 15 patients $(15 \%)$.

74 patients $(72 \%)$ terminated the outpatient treatment regularly. From the 28 patients $(28 \%)$ who terminated the treatment irregularly, 18 patients (18\%) dropped out due to relapse. 10 patients (10\%) dropped out due to familial or professional reasons.

\section{Six-Month Outcome}

At the 6-month follow-up, 97 patients (95\% of the patients who were initially included in the study) were successfully located and interviewed. Five patients (5\%) refused to participate or could not be located. According to the worst-case model, patients without follow-up information were judged as relapsed when entered into the analyses. Analyses revealed that 65 patients (64\%) were abstinent at the 6-month follow-up evaluation. 27 patients $(36 \%)$ were judged to be non-abstinent. Of those patients, $15(15 \%)$ were judged to be improved and 22 (21\%) relapsed during the last 6 months (see above: Definition of Outcome Criteria).

\section{Impact of Pre-Treatment Variables on the 6-Month Outcome}

For analyzing the impact of pre-treatment variables on the 6-month outcome (abstinent or non-abstinent), pretreatment variables between both outcome groups were compared (table 1). There were no differences concerning sociodemographic data, but a higher proportion of abstainers was more satisfied with employment status. Compared with the abstainers, non-abstainers are more likely to have a longer duration of alcohol dependence. They had a higher daily alcohol consumption in the months before treatment and were more likely to have been treated for alcohol dependence, especially inpatient treatment. During the actual treatment they were more likely to be dropped out and to be relapsed.

Concerning psychopathology, non-abstainers had statistically significant higher sum scores $(\mathrm{p}<0.05)$ in STAI II (anxiety): abstainers: 37.16 ( \pm 9.92$)$ vs. non-abstainers: 42.22 ( \pm 11.94$)$, BDI (depression) $5.45( \pm 6.71)$ vs. 9.94 $( \pm 9.74)$ and OCDS (craving for alcohol) $3.98( \pm 3.89)$ vs. 6.09 ( \pm 4.89$)$. There were no statistically significant differences concerning STAI I.

\section{Discussion}

The results of the present study indicate that outpatient treatment is an alternative and effective treatment for long-term alcohol-dependent patients: $64 \%$ patients were abstinent, $14 \%$ were improved and $22 \%$ relapsed 6 months after treatment. These results are in line with results of previous studies both examining outpatient and inpatient treatments. Studies focusing on outpatient treatment reported abstinence rates of $34-59 \%$ for the 6month outcome $[15,16], 48 \%$ for the 18 - to 24 -month outcome [3] and 52\% for the 49-month outcome [17]. 
Table 1. Differences in (A) sociodemographic pre-treatment variables and (B) alcohol-related variables between abstinent and nonabstinent patients at 6 months' follow-up

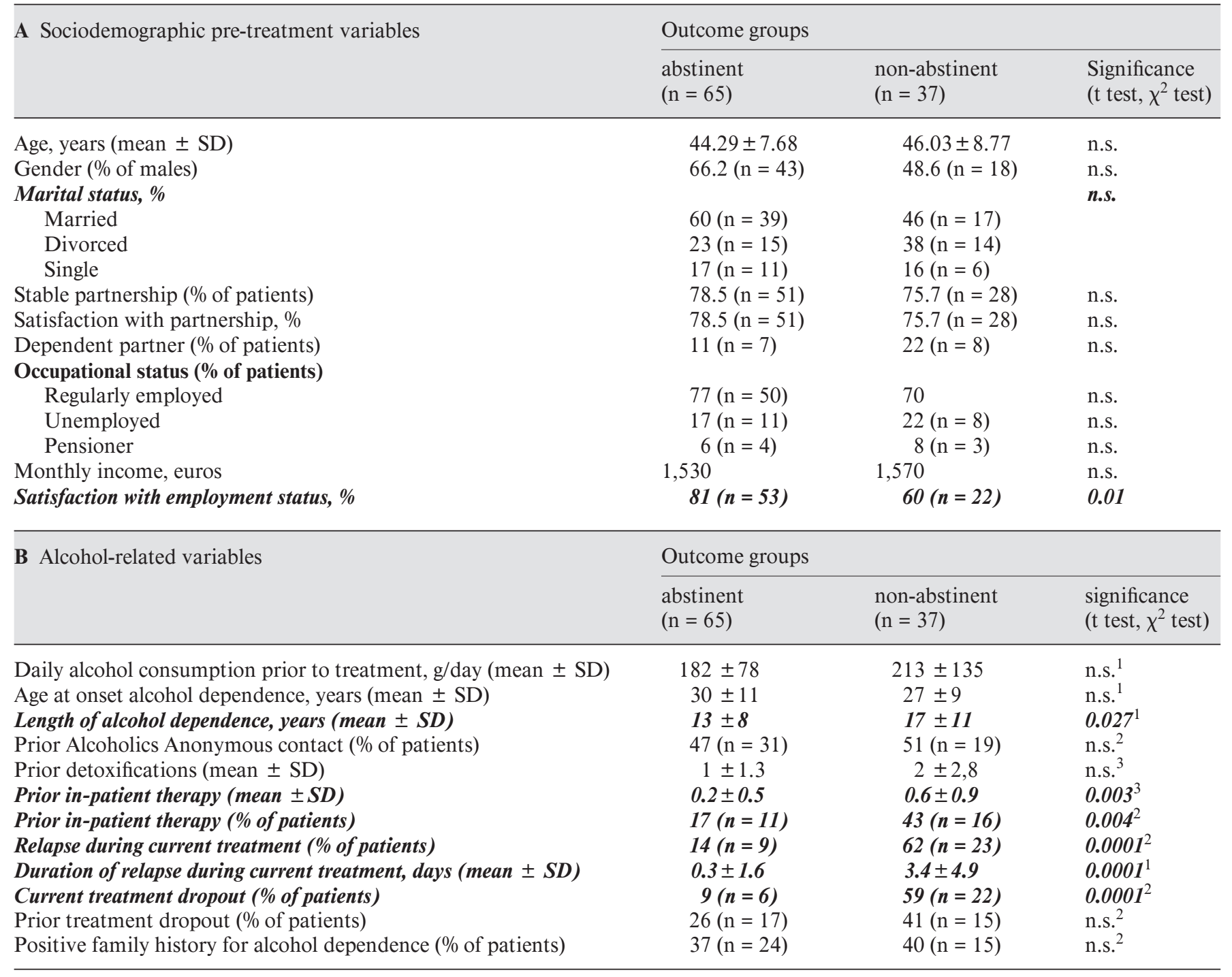

${ }^{1}$ Two-tailed t test. ${ }^{2} \chi^{2}$ test. ${ }^{3}$ Mann-Whitney U test.

With regard to comparable durations of follow-ups, results of inpatient treatments range from 40 to $60 \%$ abstinence rates [18]. Moreover, considering that many previous studies used less strict outcome criteria than the present study (i.e. some previous studies handle improvers as abstinent), the present findings clearly highlight the efficacy of the evaluated outpatient treatment program. Since the differences in outcome definitions limit the comparability of the findings between different studies, we suggest the use of uniform study designs and definition of outcome criteria as proposed by Feuerlein and Küfner [2] to improve alcoholism research on a standardized and comparable basis.

Concerning the prediction of the 6-month outcome after outpatient treatment, we found that outcome is not related to the initially assessed sociodemographic parameters. This finding, which is contradictory to the findings obtained by other studies $[19,20]$, may in part be explained by the selection criteria for the outpatient treatment which require a relatively stable social situation of 
patients (i.e. $58 \%$ of patients were married, middle-aged and $81 \%$ of patients were regularly employed). Thus, the sociodemographic characteristics of the patients investigated in the present study are probably not representative for alcohol dependents in general. The study is even limited by the relatively small sample size. On the other hand, this negative finding concerning the predictive relevance of sociodemographic parameters together with the high abstinent rates indicates that socially stable patients benefit from this kind of treatment and that indication criteria were chosen correctly. The study results are further limited by the dropout ratio of $28 \%$. But in comparison to other studies, our dropout ratio is rather low for outpatient alcohol dependents [15].

Pre-treatment variables which were found to have a negative impact (non-abstinence) on the 6-month outcome after treatment were a higher severity of alcohol dependence measured by the duration of alcohol dependence, the number of prior treatments in terms of detoxifications and inpatient treatments and a stronger alcohol craving (measured with the OCDS). Potentially these patients may benefit from more intensive alternative inpatient treatment strategies or additional anticraving substances like acamprosate. There was also prognostic impact of relapse and dropout during the current treatment for a negative outcome 6 months after treatment. This result is in line with previous studies [21-23]. Since these patients did not complete the full outpatient treatment program these findings indirectly also point to the efficacy of the treatment.

Additionally, negative outcome was associated with a significantly higher degree of psychopathological symptoms as anxiety and depression. The results do not indicate clinically relevant depression or anxiety but indicate subclinic symptoms which influence treatment and prognosis. Data of our research group showed that patients with a higher degree of psychopathological symptoms dropped out significantly more often during the current therapy [24]. We corroborate the hypothesis that patients with a higher degree of psychopathological symptoms can be integrated worse in outpatient treatments and that these patients have a negative outcome. Maybe patients should be screened before treatment and patients with a higher degree of psychopathological symptoms should be treated more intensively.

With respect to international literature, a number of reviews and meta-analyses on the efficacy of alcohol treatment have been published [25-28] but the question of whether inpatient or outpatient treatment are equally effective is still being controversially discussed. Finney et al. [29] reviewed 14 studies comparing the outcome of inpatient and outpatient treatment for alcohol use related disorders. Seven of these studies found significant setting effects on at least one drinking-related outcome variable. Five studies favored inpatient treatment and two intensive outpatient treatment. The results of these studies also suggested that patients treated in a community residential facility may show better outcomes after inpatient treatment compared to those entering treatment from the community directly. Moos et al. [30] concluded that these studies have shown either small or no differences in outcome but the patients involved in these studies tended to be residentially more stable individuals without serious concomitant psychiatric disorders.

Three major areas of patient and life context factors have been implicated as potential moderators of treatment setting effects on outcome [29]: Co-morbidity with psychiatric disorders, social stability and life context of drinking. High-intensity community programs in general have been found to be more effective than low-intensity programs. Some studies suggest that the amount of treatment may be an independent determinant of treatment, and the amount of treatment may mediate the effect of the setting on outcome [30]. Independent predictors of outcome include substance use in the facility and participation in self-help groups [31].

More recently the aspect of client heterogeneity and treatment outcome has attracted considerable attention. There is a strong trend in alcohol treatment to improve the effects of treatment by allocating or matching clients to treatment strategies meeting their specific needs [32]. The probably most ambitious and widely discussed study on this subject, the US Project Match [33], focused on the efficacy of three manual-based psychotherapeutic approaches: cognitive behavioral therapy (CBT, 12 sessions), motivational enhancement therapy (MET, 4 sessions) and twelve-step facilitation (TSF, 12 sessions). During the 1-year post-treatment period, outpatients low in psychiatric severity had a higher rate of abstinent days after TSF than after CBT. Patients with a social network supportive for drinking had more percentage days abstinent and fewer drinks per drinking day with TSF than with MET at the 3-year follow-up only. Otherwise no significant differences in treatment outcome between the three treatments could be found. While the Project Match has failed, some studies have shown that treatment matching can be effective $[34,35]$. Allocation of clients to treatment can improve abstinence, alcohol consumption, compliance and psychosocial functioning, among others. 
In summary, the results of this study indicate a favorable outcome of socially stable alcoholics in an intensive outpatient rehabilitation program. Future research in this ongoing study will focus on predictors of outcome at 12 36 months after treatment.

\section{Acknowledgement}

Funded by the Bundesversicherungsanstalt für Angestellte (BfA, Berlin).

\section{References}

1 Leune J: Daten, Fakten allgemeine Behandlungszahlen; in Deutsche Hauptstelle gegen die Suchtgefahren (ed): Jahrbuch Sucht 2002. Geesthacht, Neuland, 2002, pp 135-150.

2 Feuerlein W, Küfner H: A prospective multicenter study on inpatient treatment for alcoholics: 18- and 48-months follow-up. Eur Arch Psychiatry Neurol Sci 1989;239:144-157.

3 Soyka M, Kirchmayer C, Kotter G, John C, Löhnert E, Möller HJ: Neue Möglichkeiten der Therapie und Rehabilitation alkoholabhängiger Patienten - Katamnestische Untersuchung zur Effizienz ambulanter EntwöhnungstherapienamBeispieleinerModelleinrichtung. Fortschr Neurol Psychiatr 1997;65:407-412.

4 McLellan AT, Alterman AI, Metzger DS, Grissom GR, Woody GE, Luborsky L, O'Brien CP: Similarity of outcome predictors across opiate, cocaine and alcohol treatments: Role of treatment services. J Consult Clin Psychol 1994;62: 1141-1158.

5 Moos RH, Finney JW, Moos BS: Inpatient substance abuse care and the outcome of subsequent community residential and outpatient care. Addiction 2000;95:833-846.

6 Rounsaville BJ, Dolinsky ZS, Babor TF, Meyer RE: Psychopatholgy as a predictor of treatment outcome in alcoholics. Arch Gen Psychiatry 1987;44:505-513.

7 Soyka M, Horak M: Outpatient alcohol detoxification: Implementation efficacy and outcome effectiveness of a model project. Eur Addict Res 2004;10:180-187.

8 Soyka M, Rüster P: Modell einer ambulanten Betreuungs- und Nachsorgeeinrichtung für Alkoholkranke, Kap. 15.8; in Möller HJ (ed): Therapie psychiatrischer Erkrankungen. Stuttgart, Thieme, 2000, pp 632-639.

9 Deutsche Gesellschaft für Suchtforschung und Suchttherapie: Dokumentationsstandards 2 für die Behandlung von Abhängigen. Freiburg/ Br, Lambertus Verlag, 1992.

10 McLellan AT, Kushner H, Metzger D, Peters R, Smith I, Grissom G, Pettinati H, Argeriou M: The Fifth Edition of the Addiction Severity Index. J Subst Abuse Treat 1992;9:199-213. German version: Gsellhofer B, Küfner H, Vogt M, Weiler D: European Addiction Severity Index. EuropASI. Baltmannsweiler, Schneider Verlag, 1999.

11 Laux G, Ganzmann P, Schaffner P, Spielberger CD: Das State-Trait-Anxiety-Inventory (STAI). Weinheim, Beltz, 1981.
12 Beck AT, Rial WY, Rickels K: Short form of depression inventory: Cross-validation. Psychol Rep 1974;34:1184-1186.

13 Anton RF, Moak DH, Lathamp: The Obsessive Compulsive Drinking Scale: A self-rated instrument for the quantification of thoughts about alcohol and drinking behavior. Alcohol Clin Exp Res 1995;19:92-99. German version: Mann K, Ackermann K: Psychometrische Kennwerte der deutschen Version der Obsessive Compulsive Drinking Scale. Sucht 2000; 46:90-100

14 Elal-Lawrence G, Slade PD, Dewey ME: Predictors of outcome type in treated problem drinkers. J Stud Alcohol 1986;47:41-47.

15 Burtscheidt W, Wölwer W, Schwarz R, Strauss W, Löll A, Lüthcke H, Redner C, Gaebel W: Outpatient behaviour therapy in alcoholism: Relapse rates after 6 months. Acta Psychiatr Scand 2001;103:24-29.

16 Mundle G, Brügel R, Urbaniak H, Längle $\mathrm{G}$, Buchkremer G, Mann K: Kurz- und mittelfristige Erfolgsraten ambulanter Entwöhnungsbehandlungen für alkoholabhängige Patienten. Fortschr Neurol Psychiatr 2001;69:374-378.

17 Pfeiffer WE, Fahrner EM, Feuerlein W: Katamnestische Untersuchung von ambulant behandelten Alkoholabhängigen. Suchtgefahren 1987;33:309-320.

18 Längle G, Mann K, Mundle G, Schied HW: Ten years after - The posttreatment course of alcoholism. Eur Psychiatry 1993;8:95-100.

19 Caddy RC, Block T: Individual differences in response to treatment; in Galizio M, Maisto SA (eds): Determinants of Substance Abuse: Biological, Psychological and Environmental Factors. New York, Plenum Press, 1985, pp 317 362.

20 Emrick CD: Assertions regarding effectiveness of treatment for alcoholism. Fact or fantasy? Am Psychol 1983;38:1078-1088.

21 Battjes RJ: Similarity of clients and treatment outcome in out-patient drug-free programs. Am J Drug Alcohol Abuse 1983;9:263-279.

22 Bell DC, Williams ML, Nelson R: An experimental test of retention in residential and outpatient programs. Am J Drug Alcohol Abuse 1994;20:331-340.

23 Nagy PD: Intensive Outpatient Treatment for Alcohol and Other Drug Abuse. DHHS Publ SMA 94-2077. Rockville, US Department of Health and Human Services, 1994
24 Soyka M, Hasemann S, Scharfenberg CD, Löhnert B, Bottlender M: New possibilities in treatment and rehabilitation of alcohol-dependent patients - A catamnestic study on the efficiency of outpatient treatment programmes demonstrated by a model procedure. Nervenarzt 2003;74:226-234.

25 Emrick CA: A review of psychologically oriented treatment of alcoholism. II. The relative effectiveness of different treatment. J Stud Alcohol 1975;36:88-108.

26 Marlatt GA, Gordon JR: Relapse Prevention. Maintenance Strategies in the Treatment of Addictive Behaviors. New York, Guilford, 1985

27 Miller WR, Brown JM, Simpson TL Handmaker NS, Bien TH, Luckie LF: What works? A methodological analysis of alcoholism treatment outcome literature; in Hester RH, Miller WR (eds): Handbook of Alcoholism Treatment Approaches: Effective Alternatives. New York, Allyn \& Bacon, 1995, pp 12-44.

28 Miller WR, Hester RK: The effectiveness of alcoholism treatment. What research reveals; in Miller WR, Heather N (eds): Treating Addictive Behaviors. Processes of Change. New York, Plenum Press, 1986, pp 121-174.

29 Finney JW, Hahn AC, Moos RH: The effectiveness of inpatient and outpatient treatment for alcohol abuse: The need to focus on mediators and moderators of setting effects. Addiction 1996;91:1773-1796.

30 Moos RH, Mertens JR, Brennan PL: Rates and predictors of four-year readmission among late-middle-aged and older substance abuse patients. J Stud Alcohol 1994;55:561-570.

31 Ouimette PC, Finney JW, Moos RH: Twelvestep and cognitive-behavioral treatment for substance abuse: A comparison of treatment effectiveness. J Consult Clin Psychol 1997;65: 230-240.

32 Mattson EM: Patient-treatment matching: Rationale and results. Alcohol Health Res World 1994; 18:287-295.

33 Project MATCH Research Group: Matching alcoholism treatments to patient heterogeneity: Project MATCH posttreatment drinking outcomes. J Stud Alcohol 1997;58:7-29

34 McLachlan JFC: Therapy strategies, personality orientation and recovery from alcoholism. Can Psychiatr Assoc 1974;19:25-30.

35 McLellan AT, Woody GE, Luborsky L, O'Brien $\mathrm{CP}$, Druley KA: Increased effectiveness of substance abuse treatment: A prospective study of patient-treatment 'matching'. J Nerv Ment Dis 1983;171:597-605. 